\title{
Evaluation of medication adherence and its predictors among Ethiopians in Washington, DC.
}

Raniya Ali Al-Matari ( $\nabla$ ralmatari@gmail.com )

Howard University https://orcid.org/0000-0003-3452-9765

Mary Maneno

Howard University

La' Marcus Wingate

Howard University

Bisrat Hailemeskel

Howard University

Monika Daftary

Howard University

Earl Ettienne

Howard University

Ahmed Moen

Howard University

Augusto Jeronimo

Howard University

Gail Nunlee-Bland

Howard University

Karen Wyche

Virginia Science and Technology

Ermias Tilahun

Howard University

Tamrat Retta

Howard University

Research article

Keywords: Medication adherence, Ethiopian, Simplified Medication Adherence Questionnaire

Posted Date: December 12th, 2019

DOI: https://doi.org/10.21203/rs.2.18836/v1 
License: (c) (i) This work is licensed under a Creative Commons Attribution 4.0 International License. Read Full License 


\section{Evaluation of medication adherence and its predictors among Ethiopians in Washington,}

DC.

Raniya Ali Al-Matari, Ph.D

(Corresponding author)

Howard University College of

Pharmacy Department of Clinical

and Administrative Pharmacy

Sciences

2300 4th, NW, Washington, DC

20059 Email: ralmatari@gmail.com

Mary K. Maneno, Ph. D

Howard University College of

Pharmacy

Department of Clinical and

Administrative Pharmacy Sciences

2300 4th, NW, Washington, DC

20059

Email: mary.maneno@howard.edu

Monika N. Daftary, PharmD

Howard University College of

Pharmacy

Department of Clinical and

Administrative Pharmacy Sciences

2300 4th, NW, Washington, DC

20059

Email: mdaftary@howard.edu

Gail Nunlee-Bland, MD

Howard University Hospital

2041 Georgia Ave NW \# 4000,

Washington, DC 20060

Email: gnunlee-bland@howard.edu

Karen Wyche, Ph.D

Virginia Science and Technology

Campus Innovation Hall

45085 University Dr.

Suite 201E

Ashburn, Virginia 20147

United States

Email:kwyche@gwu.edu
Earl B. Ettienne, LDP, MBA, R. Ph

Howard University College of Pharmacy

Department of Clinical and Administrative

Pharmacy Sciences

2300 4th, NW, Washington, DC 20059

Email: earl.ettienne@howard.edu

La'Marcus Wingate, $\mathrm{Ph}$. D

Howard University College of Pharmacy

Department of Clinical and Administrative Pharmacy Sciences

2300 4th, NW, Washington, DC 20059

Email: lamarcus.wingate@ howard.edu

Bisrat Hailemeskel PharmD

Howard University College of Pharmacy

Department of Clinical and Administrative Pharmacy Sciences

2300 4th, NW, Washington, DC 20059

Email: bhailemeskel@howard.edu

Tamrat Retta MD

Towers, 2041 Georgia Ave NW \#5100,

Washington, DC 20060

Email: tretta@howard.edu

Ahmed Moen, DrPH

Howard University, College of Nursing and Allied Health 516 Bryant St NW, Washington, DC 20059

Email: amoen@howard.edu

Jeronimo Augusto, MSHA

Howard University - Office of the Provost 2400 Sixth Street, NW, Washington, DC 20059 Email: jeronimo.augusto@howard.edu

Ermias Lemma Tilahun

Howard University College of Pharmacy 2300 4th, NW, Washington, DC 20059

Email: ermias.tilahun@bison.howard.edu 


\section{ABSTRACT}

Background: Non-adherence to medication can lead to poor health outcomes. Studies report the rates of medication adherence for US-born persons, but little is known about estimates among foreign-born persons; those of Ethiopian descent residing in the US. This study addresses this issue by examining medication adherence and associated factors among Ethiopians.

Methods: A cross-sectional study was conducted to estimate the level of medication adherence and to assess its predictors among urban adult Ethiopians who were administered a translated and validated Amharic-version of the Simplified Medication Adherence Questionnaire (SMAQ). The participant had to be 1) Ethiopian 2) understand the Amharic language, 3) ages 18 to 85 years, and 4) taking medications continuously to manage a medical condition. Descriptive statistics were used to describe study variables. Logistic regression analysis was used to evaluate predictors of medication adherence. Odds ratios and 95\% confidence intervals were also estimated. All analysis was conducted using Statistical Package for Social Sciences (SPSS) for windows version 19 at an alpha level of 0.05 .

Results: A total of 163 Ethiopians with chronic diseases were recruited. Their mean age was 56.6 years and the majority were female $54 \%$ and born in Ethiopia (95.7\%). The overall adherence level in this population was $34.4 \%$. Participants who were less likely to adhere to medications included those who had difficulty in communicating in English (p-value=0. 019) Self-reported high activity level, healthy diet, belief in holy water and spiritual healing, and higher education levels were also found to be statistically significant predictors of medication adherence adjusting for all other variables.

Conclusion: Difficulty in communicating in English was significantly related to poor medication adherence in Ethiopian adults and indicates that health care providers should develop patient 
educational materials in Amharic to better serve these patients. Factors significantly related to medication adherence seem to cluster in self-care (healthy eating, not in relying on some cultural practices for healing as a replacement for medications and being active) in addition to attaining college or above education. Consideration of these factors in developing treatment plans and interventions for this diverse population may yield better therapeutic outcomes.

Keywords: Medication adherence, Ethiopian, Simplified Medication Adherence Questionnaire 


\section{Background}

Ethiopia is the third largest African nation represented among US immigrants (1),(2) and with the largest number of person's literate in the Amharic language. Washington, D.C. has the highest number of Ethiopian immigrants with estimated at 37,200 persons. (2),(3) Ethiopians reside in the Washington metropolitan area because they believe that it is a place to acquire an education, seek work opportunities, have access to better transportation, obtain a better quality of life, and have access to various Ethiopian restaurants and markets. In general, they feel more welcomed by local institutions in this area. (2)

Despite their long history of immigrating and acculturating into the Washington metropolitan area, most of the Ethiopian immigrants do not communicate well in English. (3) As a result, accessing health care and any healthcare-related resources is challenging. Considering that Ethiopians in the US have documented the burden of chronic disease. (1),(4),(5), such language challenges could present several barriers to care. Other barriers include stigma, education, use of cultural practices such as holy water for healing, lack of knowledge of healthcare services, lack of insurance, fear of clinical testing, denial, low perception of disease risk, and engagement in high-risk behaviors that may discourage them from accessing healthcare resources. $(1,6,7)$ Given the well-established relationship between lack of health care access and non-adherence, $(8,9)$ evaluating the level of medication adherence in this population and the effect of all the aforementioned factors would be important. Little is known about the medication adherence rate among persons of Ethiopians in the US. Furthermore, little data exist on the level of impact that difficulty communicating in English and other sociodemographic and cultural factors have on medication adherence in this population. Considering these knowledge gaps this study evaluated 
the adherence rate among persons of Ethiopian descent and its predictors using a translated and validated Amharic version of the Simplified Medication Adherence Questionnaire (SMAQ).

\section{Methods}

\section{Study Design and Population}

Cross-sectional study design was conducted in 2017 to evaluate factors that predict medication adherence among persons of Ethiopian descent. Participants were recruited from the Washington DC metropolitan area. Recruitment sites were: Urban hospital and community-based agency providing services to the Ethiopian community. To be eligible, a participant had to be 1) Ethiopian 2) understand the Amharic language, 3) ages18 to 85 and 4) taking medications continuously to manage their medical condition. An opportunity to participate in a raffle ticket drawing to win 50 dollars was offered as study incentive. This study received approval from the Howard University Institutional Review Board and the Howard University Hospital.

\section{Study Measures}

The primary outcome of this study was medication adherence, as measured by the Amharicversion SMAQ. A combined questionnaire in English was developed. It included all study variables and the validated English version Simplified Medication Adherence scale. The SMAQ is a six-item, short self-report questionnaire determining complete medication adherence, and accuracy of medication intake (e.g. number of missed doses) among patient with chronic diseases. (10) The SMAQ contains 3-items from the Morisky scale questionnaire 1. Do you ever forget to take your medication? 2. Are you careless at times about taking your medication? 3 . Sometimes if you feel worse, do you stop taking your medicines? plus an additional three items.

4. Thinking about the last week. How often have you not taken your medicine? 5. Did you not take any of your medicines over the past weekend? 6. Over the past 3 months, how many days 
have you not taken any medicine at all? (10) For the SMAQ questions, 1-3 and 5, a total score of 1 was given if the participant responds "Yes" to any of the questions. If the participant responds "No" to any of the questions a total score of $\mathbf{2}$ is received. For question 4, a total score of $\mathbf{2}$ was given if the participant responds Never. If the participants respond to $\geq 1$ time, then the participants received a score of 1 . For question 6 , a total score of 2 was given if the participant responds $\leq \mathbf{2}$ days. If the participant responds $>\mathbf{2}$ days, then the participant received a score of $\mathbf{1}$. If the participant receives a total score of 12 then the patient is considered an adherent to medication. If the participant receives a total score of $\mathbf{1 1}$ and below, then the patient is considered non-adherent to medication. (11) The English version of the medication adherence scale and all other survey items were subsequently translated into the Amharic language following the method proposed by Morisky. (12) The Amharic version of the SMAQ was then validated in a separate pilot study currently under journal review and was found to have acceptable psychometric properties (Cronbach alpha=0.653). (13)

To measure knowledge responses to the following Likert type questions were used: Do you know all the names of medicine that you take every day? Do you know the dose of each medicine that you take every day? Do you know the side-effects of the medicine? (14) Other study measures collected included socio-demographic and clinical variables including age, gender, marital status, number of diseases, alcohol usage, medication knowledge, followed unhealthy diet, smoking, number of pills taken daily, complementary and alternative medicine usage, and, duration of complementary and alternative medicine, patient-provider relationship, education level, social support, length of years in the US, length of medication, income, transportation, medication adherence, holy water and spiritual healing, country of birth, state you 
live in, illegal drugs, activity level, consultation of medication, difficulty in communicating in English, and drug coverage.

\section{Operational Definitions}

Being fluent in Amharic was defined as someone who could understand (speak and hear) the language. This definition was used because some native speakers who can hear and speak Amharic without being able to write or read in the Amharic alphabet. An Ethiopian person was operationally defined as a person who identified themselves as having one or more biological Ethiopian parents. Additionally, a person who uses complementary or alternative medicine is someone who uses anything to treat a condition except using standard medication or belief in holy water and spiritual healing.

\section{Data collection procedures}

After obtaining informed consent in Amharic survey data was collected through an AudioComputer Assisted Self Interviewing System (ACASI). This method was selected because it accommodates participants' privacy, incorporates varying levels of language literacy, and can be used with different languages. (15-22). In this study, the responses were collected after participants read the question text in the Amharic alphabet or listened to the voice recording stating the question in the Amharic language. The participants were directed to a private dedicated space at the recruitment locations where the survey was taken, given laptops along with headphones, and instructed how to use the ACASI. A facilitator was present to answer any questions related to the use of the ACASI system. Once data was collected in the ACASI system, it was automatically transferred to the study database for analysis.

\section{Statistical Analysis}


Descriptive statistics including means and percentages were estimated for continuous and categorical variables respectively. Simple and multiple logistic regression was conducted to evaluate the predictors of medication adherence. Criteria for multivariable model entry of a variable from the simple logistic regression was a significance level of $p<0.20$ or variable that was clinically important. For the first final reduced model selected variables were included. Both adjusted and unadjusted odds ratios (ORs) with their 95\% confidence intervals were reported. All analyses were performed using the Statistical Package for Social Sciences (SPSS) for Windows version 23 at an alpha level of 0.05 .

\section{Results}

\section{Participant Characteristics}

A total of 163 adult Ethiopians with chronic diseases were included in this study. The mean age was 56.6 years $( \pm 14.3)$ and the average number of years lived in the United States of America was 10.1 years $( \pm 10.3)$. A majority of the participants were female $54.0 \%)$, were married $(61.3 \%)$ and were born in Ethiopia (95.7\%). Educational level varied: $27.0 \%(\mathrm{~N}=44)$ earned college degree, 24.5\% ( $\mathrm{N}=40)$ completed high school, and 8.0\% $(\mathrm{N}=13)$ never attended school. Geographically, 58.9\% ( $\mathrm{N}=96$ ) of the participants resided in District of Columbia at the time of the survey followed by $23.9 \%(\mathrm{~N}=39)$ in Virginia, and $10.4 \%(\mathrm{~N}=17)$ in Maryland as obtained in Table 1

Findings from health and socio-behavioral characteristics of the study population showed that about half did not have drug coverage 52.1The majority of medications were for chronic diseases diabetes $32.5 \%(\mathrm{~N}=53)$ and high blood pressure $27.0 \%(\mathrm{~N}=44)$. Majority of participants did not take illegal drugs $(97.5 \% ; \mathrm{N}=159), 90.8 \%(\mathrm{~N}=148)$, did not drink alcohol $(72.4 \% ; \mathrm{N}=118)$, and 
did not smoke $(90.2 \%$; $(\mathrm{N}=147)$. Additionally, their activity level was moderate $47.9 \%(\mathrm{~N}=78)$ and never followed an unhealthy diet $(\mathrm{N}=75 ; 46 \%)$.

\section{Cultural and Psychological Characteristics}

Almost half of the participants, 48.5\% (N=79) have difficulty in communicating in the English language. The family and emotional support they receive is very high $78.6 \%(\mathrm{~N}=128)$. About half of them trusted their doctor to put their medical needs above all other considerations when treating their medical problems (49.7\% Agreed) $(\mathrm{N}=81)$. Culturally, a significant number of participants reported belief in holy water and spiritual healing, $(81.0 \%(\mathrm{~N}=132)$. In contrast, few of the participants reported using complementary and alternative medicine $(23.3 \%(\mathrm{~N}=38)$.

Findings on Medication Knowledge and Medication Adherence

Participants overall adherence rate was $34.4 \%(\mathrm{~N}=56)$ were adherent to medication according to the SMAQ. Specific adherence related items evaluated using the 6-item SMAQ are illustrated in Table 2. The overall medication knowledge score was 25.0, out of a maximum possible total of 30. The medication knowledge items included the knowledge of medication names (Average Score $=7.9$ out of 10 ), side-effects (Average Score $=8.0$ out of 10), and dosage (Average Score 9.0 out of 10) of their medications.

\section{Findings of medication adherence predictors}

Table 3 summarizes the predictors of medication adherence. As shown, difficulty in communicating English, college degree, graduate degree, following an unhealthy diet, high activity level, and holy water and spiritual healing beliefs were statistically significant predictors of medication adherence. Of note, persons who had difficulty in communicating in English had lower odds of adhering to medication compared to those who did not have difficulty in communicating in English adjusting for all other variables $(\mathrm{OR}=0.32 ; \mathrm{CI}=0.13-0.83)$. Similarly, 
participants who have college-level degree or higher had lower odds of adhering to medication compared to participants who have grade 12 and lower adjusting for all other variables $(\mathrm{OR}=0.36 ; \mathrm{CI}=0.20-0.64)$. Factors that increased the odds of medication adherence include a lack of belief in holy water and spiritual healing and having a high physical activity level. Specifically, participants who did not believe in holy water and spiritual healing had 8 times the odds adhering to medication compared to participants who did not adjust for all other variables. Similarly, participants with high physical activity level had higher odds of adhering to medication compared to those with low to moderate activity level adjusting for all other variables $(\mathrm{OR}=4.11 ; \mathrm{CI}=1.22-13.91)$. Collectively the study variables explained $36.8 \%$ of the variability of medication adherence.

\section{Discussion}

To our knowledge, this study is the first to assess the level of medication adherence among Ethiopians in the United States. Of note, this study reported an adherence level of 34.4\% (N=56) which was less than the expected optimal level of adherence for chronic conditions (80.0\%). (23, 24) Comparison studies on the same population have been conducted; however, both studies were conducted in Ethiopia and were related to mental health and HIV/AIDS. In the mental illness study conducted in Ethiopia, Ethiopian patients had an adherence rate of 73.5\%. (25) In the other study by Lifson conducted in Ethiopia, Ethiopians with HIV/AIDS had high levels of adherence (95\%). (26) This study found a much lower adherence rate when compared with these findings which could be due to differences in disease state as well as setting. The effects of limited acculturation to the US could also be potential reasons for our lower estimate. This conclusion is specifically supported by the study's predictive effects of difficulty communicating in English a proxy for acculturation. Persons with difficulty communicating in English had lower 
odds of medication adherence $(\mathrm{OR}=0.32 ; \mathrm{CI}=0.13-0.83)$. This finding is consistent with a study done by Karliner et al., (2012) on the immigrant population in the USA. The study showed that participants with limited English proficiency had lower odds of understanding medication category (OR 0.63; CI 0.42-0.95). (27) The findings are also similar to literature reviews have also shown that difficulty in communicating in English influences medication adherence. In these studies, difficulty in communicating in English has led to a lack of understanding of disease severity and medication instructions, as well as a lack of initiating doctor's visits. $(5,28)$. Collectively these findings further support the need to translate Amharic version instruments used in clinics to measure adherence and other patient-reported outcomes to better assist with patient care.

Medication knowledge was not a significant predictor of medication adherence among Ethiopians $(\mathrm{OR}=1.00 ; \mathrm{CI}=0.95-1.05)$. These findings were surprising particularly since most of the population had a high knowledge $(83.3 \%)$. The lack of predictive effect of knowledge in this study contrasts trends observed in two other studies by Balfour et al., and Hareri et al. In the study by Balffour, patients who did not know about their medications had lower odds of adhering to medication. $(29,30)$ In the Hareri et al's study conducted among Ethiopians taking hypertensive medications, knowledge was a significant predictor of medication adherence. These findings point to a need for clinicians to not consider medication knowledge level as a mitigating factor for medication adherence in this population.

An interesting predictor of adherence observed in this study was the use of holy water and spiritual healing. Specifically, persons of Ethiopian descent who reported belief in holy water and spiritual healing were shown to have lower odds of adhering to medication compared to those who did not. This was the strongest predictor of medication adherence among Ethiopians. 
This finding is consistent with findings from several studies on health-related outcomes in this population. $(4,31)$ Bezabe et al., (2013) stated that the majority of Ethiopians regardless of their religious faith believe that holy water and prayer is the cure for all the illnesses. (31) Similarly, Ethiopian patients who have HIV/AIDS have been told by their religious leaders to stop taking their HIV/AIDS medications and drink holy water and fast instead. (31) In light of these findings, it is important for clinicians to ask patients on the use of holy water and spiritual healing. Doing so would allow for interventions that would encourage taking their medications along with holy water and spiritual healing. Additional educational interventions on the importance of taking medications can also be done among religious leaders who are well respected in the community.

Surprisingly, our findings indicated that higher education level among persons of Ethiopian descents had lower odds of adhering to medication. These findings were similar to those by Norman et al., and Thames et al which showed that there is no association between higher education and high medication adherence. (9),(32) In contrast, a study in the US showed that persons who have higher education levels and higher income are more likely to make a wiser decision about their health. (33). The contrast in our study findings could also point to deeper issues with acculturation where persons with foreign education may have high socio-economic status in the US due to issues of credential recognition. While this study did not distinguish between the education received locally or internationally it was apparent that the level of education level did not translate into better socio-economic status. Nearly $46 \%$ of our study population had a high school education or higher; however, $64 \%$ overall had incomes $<\$ 20,000$. This may suggest that lack of medication adherence is related to lack of money to buy purchase 
prescribed medications. In light of this evidence, clinicians need to address the importance of medication adherence to patients of Ethiopian descent regardless of their education level. Surprisingly the number of pills and the duration of medication use did not show a predictive effect in this studied Ethiopian population. A study by Alene et al., (2012) conducted in Ethiopia, showed that pill burden and duration of medication were significant factors of medication adherence among this population. (34) Additionally, a study in HIV/AIDS patients $(35,36)$ and patients with cardiovascular disease (37) showed that pill burden was a significant predictive factor of medication adherence. However, in this study Ethiopians did not have an issue adhering to medication use by taking more than one pill to manage their condition. Differences in findings again could be related to disease state as well as study setting. More studies are needed to confirm the true effect of pill burden among persons of Ethiopian descent living in the United States.

\section{Study limitations}

There are few limitations in this study; first, the study design was cross-sectional and therefore no inference on causality can be made. Second, convenient sampling (non-probability sampling) was used in this study. This was done because this population tended to congregate in their cultural locations; findings of this study may not be generalized to all persons of Ethiopian descent in the (District of Columbia, Maryland, Virginia) DMV area. Third, all variables were collected via self- report of the individual and there may be the potential for reporting bias. This is particularly suspected because no patient-reported having HIV/AIDS despite knowing that there is a high prevalence of the condition in this community based upon the literature. Fourth, because the majority of persons in the study were recruited from the Ethiopian community center; the participants may have provided a false response regarding their income since the 
participants were coming to the community center to apply for health insurance. To be eligible for health insurance applicants had to earn less than $\$ 10,000$ or have no income. Fifth, similar to the pilot study recall bias may also be another limitation as an individual may not remember whether they did not take their medication in the past. Finally, the item of unhealthy diet was not specific to what kind of unhealthy eating habits the question was trying to identify. Unhealthy eating was not further defined; as it could have meant not following the food pyramid or eating junk food to the respondents and may have led to mixed reporting.

\section{Conclusion}

A low medication adherence rate was observed among persons of Ethiopian descent. Overall factors such as difficulty in communicating in English, believing in holy water and spiritual healing, high activity level, following an unhealthy diet rarely/sometimes/often/always, having a college degree or higher were significantly predictive factors of medication adherence among persons of Ethiopian descent. Consideration of these factors in developing treatment plans and interventions for this patient population may yield better therapeutic.

\section{Abbreviations}

ACASI: Audio-Computer Assisted Self Interviewing System; ORs: ODDS RATIO;

SMAQ: Simplified Medication Adherence Questionnaire; SPSS: Statistical Package for Social Sciences; US: United States of America.

\section{Declarations}

\section{Ethical approval and consent to participate}

The research was approved by the Howard University Institutional Review Board reference number 15-PHARM/CPHARM-12 and all procedures performed in studies involving human participants were in accordance with the ethical standards of the institutional and research 
committee and with the 1964 Helsinki declaration and its later amendments or comparable ethical standards. Informed consent was obtained from all individual participants included in the study.

\section{Consent to publish}

Not applicable.

\section{Availability of data and materials}

The datasets used and/or analyzed during the current study are available from the corresponding author on reasonable request.

\section{Competing interest}

The authors declare that they have no competing interests in this section.

\section{Funding}

This project was supported (in part) by the National Institute on Minority Health and Health Disparities of the National Institutes of Health under Award Number G12MD007597. The content is solely the responsibility of the authors and does not necessarily represent the official views of the National Institutes of Health.

\section{Author Contributions}

Writing the abstract, introduction, method, result, and discussion of the manuscript: RA. Guide in the writing process and editing of the manuscript: MM. Analysis and interpretation of data: MM: RA. Writing, reviewing and editing manuscript: MM: MD: KW: EE: RA: ET: AM: JA:

BH: TR: LW: GN. All authors read and approved the final manuscript.

\section{Acknowledgments}

Not applicable 
Table 1. Socio-Demographic and General Health Characteristics of participants

\begin{tabular}{|l|l|}
\hline & $\mathrm{N}(\%)$ \\
\hline Age (Mean \pm SD) & $56.6 \pm 14.3$ \\
\hline Gender & \\
\hline Male & $75(46.0)$ \\
\hline Female & $88(54.0)$ \\
\hline Marital Status & \\
\hline Married & $100(61.3)$ \\
\hline Divorced & $13(8.0)$ \\
\hline Widowed & $32(19.6)$ \\
\hline Separated & $3(1.8)$ \\
\hline Never married & $15(9.2)$ \\
\hline Education level & \\
\hline Never attended school & $13(8.0)$ \\
\hline Elementary & $17(10.4)$ \\
\hline Some high school & $18(11)$ \\
\hline Grade 12 (high school) & $40(24.5)$ \\
\hline Some college & $20(12.3)$ \\
\hline College Degree & $44(27.0)$ \\
\hline Graduate Degree & $11(6.7)$ \\
\hline Number of years lived in the United States of America (Mean \pm SD) & $10.1 \pm 10.3$ \\
\hline State or jurisdiction live in & \\
\hline District of Columbia & $96(58.9)$ \\
\hline Maryland & $17(10.4)$ \\
\hline Virginia & $39(23.9)$ \\
\hline Annual household income from all sources: & \\
\hline Less than \$10,000 & $80(49.1)$ \\
\hline \$10,000- \$20,000 & $25(15.3)$ \\
\hline \$20,001- \$30,000 & $15(9.2)$ \\
\hline \$30,001- \$40,000 & $17(10.4)$ \\
\hline \$40,001- \$50,000 & $9(5.5)$ \\
\hline \$50,001- \$60,000 & $10(6.1)$ \\
\hline \$60,001- \$75,000 & $2(1.2)$ \\
\hline \$75000 or more & $5(3.1)$ \\
\hline Unhealthy diet & \\
\hline Fever & $75(46.0)$ \\
\hline Rarely & $64(39.3)$ \\
\hline Sometimes & $20(12.3)$ \\
\hline Often & $3(1.8)$ \\
\hline Always & $1(0.6)$ \\
\hline
\end{tabular}




\begin{tabular}{|l|c|}
\hline What is your physical activity level? & $\mathrm{N}(\%)$ \\
\hline Low & $65(39.9)$ \\
\hline Moderate & $78(47.9)$ \\
\hline High & $20(12.3)$ \\
\hline Illegal drugs & \\
\hline Yes & $4(2.5)$ \\
\hline No & $159(97.5)$ \\
\hline Length of medication & \\
\hline Days & $10(6.1)$ \\
\hline Weeks & $9(5.5)$ \\
\hline Months & $31(19.0)$ \\
\hline Year & $113(69.3)$ \\
\hline Believe in holy water and spiritual healing & \\
\hline Yes & $132(81.0)$ \\
\hline Use any complementary and alternative medicine & \\
\hline No & $125(76.7)$ \\
\hline Difficulty communicating in English & \\
\hline Yes & $79(48.5)$ \\
\hline No & $84(51.5)$ \\
\hline How often do you use complementary medicine to western medicine & \\
\hline Never & $101(62.0)$ \\
\hline Rarely & $38(23.3)$ \\
\hline Always & $1(0.6)$ \\
\hline Transportation & \\
\hline Yes & $105(64.4)$ \\
\hline No & $58(35.6)$ \\
\hline Smoke & \\
\hline No & $147(90.2)$ \\
\hline Alcohol & \\
\hline Yes & $45(27.6)$ \\
\hline No & $118(72.4)$ \\
\hline Country of birth & $156(4.3)$ \\
\hline Ethiopia & $\mathrm{N}(\%)$ \\
\hline Other & $7(4.3)$ \\
\hline Number of diseases & $72(44.2)$ \\
\hline One & $47(28.8)$ \\
\hline Two & $44(27.0)$ \\
\hline More than two & \\
\hline Emotional help and support & \\
\hline Very Strongly Disagree & \\
\hline Strongly Disagree & \\
\hline & \\
\hline
\end{tabular}




\begin{tabular}{|l|c|}
\hline Mildly Disagree & $8(4.9)$ \\
\hline Neutral & $12(7.4)$ \\
\hline Mildly Agree & $5(3.1)$ \\
\hline Strongly Agree & $42(25.8)$ \\
\hline Very Strongly Agree & $81(49.7)$ \\
\hline $\begin{array}{l}\text { Do you trust your doctor to put your medical needs above all other } \\
\text { considerations when treating your medical problems }\end{array}$ & \\
\hline Strongly Disagree & $22(13.5)$ \\
\hline Disagree & $11(6.7)$ \\
\hline Neutral & $25(15.3)$ \\
\hline Agree & $54(33.1)$ \\
\hline Strongly Agree & $51(31.3)$ \\
\hline
\end{tabular}

Table 2. Medication-Related Findings

\begin{tabular}{|l|c|}
\hline Amharic SMAQ Item Responses & $\mathrm{N}(\%)$ \\
\hline Ever forget to take your medications & \\
\hline Yes & $71(43.6)$ \\
\hline Careless sometimes about taking medications & $60(36.8)$ \\
\hline Yes & \\
\hline Sometimes if you feel worse do you stop taking your medicines & $17(10.4)$ \\
\hline Yes & \\
\hline $\begin{array}{l}\text { Thinking about last week. How often have you not taken your } \\
\text { medicine }\end{array}$ & $131(80.4)$ \\
Never & $22(13.5)$ \\
$1-2$ times & $5(3.1)$ \\
$3-5$ times & $2(1.2)$ \\
6-10 times & $3(1.8)$ \\
More than 10 times & \\
\hline Did you not take any of your medicine over the past weekend? & $29(17.8)$ \\
\hline Yes & \\
\hline Over the past 3 months, how many days have you not taken any & \\
medicine at all? & $124(76.1)$ \\
\hline$<2$ days & \\
\hline Other Medication-related characteristics & \\
\hline Adherence & $56(34.4)$ \\
\hline \multicolumn{1}{|l}{ Yes } & $107(65.6)$ \\
\hline \multicolumn{1}{|l}{ No } & \\
\hline Pills in a day & $69(42.3)$ \\
\hline One & $38(23.3)$ \\
\hline Two & $56(34.4)$ \\
\hline More than 2 & $25.0 \pm 6.6$ \\
\hline Medication knowledge score (Mean \pm SD) & $123(75.5)$ \\
\hline Who consults you better about your medication? & \\
\hline Physician & \\
\hline
\end{tabular}




\begin{tabular}{|c|c|}
\hline Nurse & $7(4.3)$ \\
\hline Pharmacist & $33(20.2)$ \\
\hline Drug Coverage & \\
\hline No & $85(52.1)$ \\
\hline
\end{tabular}

Table 3. Predictive Factors of Adherence among persons of Ethiopian Descent

\begin{tabular}{|l|l|l|}
\hline Variables & $\begin{array}{l}\text { OR adjusted } \\
\mathbf{( 9 5 \% ~ C I ) ~}\end{array}$ & $\begin{array}{l}\text { P-value } \\
\text { adjusted }\end{array}$ \\
\hline Difficulty in communicating in English & & \\
\hline Yes & $\mathbf{0 . 3 2 ( 0 . 1 3 - 0 . 8 3 )}$ & $\mathbf{0 . 0 1 9 *}$ \\
\hline No & Reference & Reference \\
\hline Age & $1.01(0.98-1.04)$ & 0.466 \\
\hline Education level & Reference & Reference \\
\hline Grade 12 and lower & $1.29(0.72-2.33)$ & 0.395 \\
\hline Some college degree & $0.36(0.20-0.64)$ & $0.001^{*}$ \\
\hline College or higher degree & & \\
\hline Prescription drug coverage & Reference & Reference \\
\hline Yes & $1.85(0.75-4.60)$ & 0.183 \\
\hline No & & \\
\hline Number of pills & Reference & Reference \\
\hline One & $0.44(0.18-1.09)$ & 0.074 \\
\hline Two/More & & \\
\hline Follow unhealthy diet & $2.60(1.09-5.97)$ & $0.031^{*}$ \\
\hline Never & Reference & Reference \\
\hline Rarely/Sometimes/Often/Always & $0.98(0.92-1.04)$ & 0.482 \\
\hline Medication Knowledge & & \\
\hline Holy water and spiritual healing & Reference & Reference \\
\hline Yes & $8.87(3.04-25.85)$ & $0.000^{*}$ \\
\hline No & & \\
\hline Activity level & Reference & Reference \\
\hline Low/Moderate & $4.11(1.22-13.91)$ & $0.023^{*}$ \\
\hline High & & \\
\hline $\begin{array}{l}\text { Do you trust your doctor to put your medical } \\
\text { needs above all other considerations when } \\
\text { treating your medical problems }\end{array}$ & & \\
\hline Very strongly agree & $1.12(0.47-2.65)$ & 0.805 \\
\hline Very strongly disagree/Neutral & Reference & Reference \\
\hline $\begin{array}{l}\text { Do you work hard to keep your disease a secret } \\
\text { from others? }\end{array}$ & & \\
\hline Strongly agree & $0.88(0.27-2.82)$ & 0.830 \\
\hline Strongly disagree/Neutral & Reference & Reference \\
\hline & & \\
\hline
\end{tabular}




\begin{tabular}{|l|l|l|}
\hline $\begin{array}{l}\text { Do you get the emotional help and support you } \\
\text { need from your family }\end{array}$ & & \\
\hline Strongly agree & $0.83(0.30-2.30)$ & 0.714 \\
\hline Strongly disagree/Neutral & Reference & Reference \\
\hline Complementary medication & & \\
\hline Yes & Reference & Reference \\
\hline No & $0.92(0.34-2.53)$ & 0.866 \\
\hline Length of time on medication & & \\
\hline Days/Weeks/Months & Reference & Reference \\
\hline Years & $2.36(0.85-6.57)$ & 0.099 \\
\hline$*$ p-value $<0.05$ & & \\
\hline
\end{tabular}




\section{References}

1. Willis LA, Opoku J, Murray A, West T, Johnson AS, Pappas G, et al. Diagnoses of Human Immunodeficiency Virus (HIV) Infection Among Foreign-Born Persons Living in the District of Columbia. J Immigr Minor Health. 2013 Jul 30. PubMed PMID: 23897303. Epub 2013/07/31. Eng.

2. The Washington post. African immigrant population doubling each decade. D.C. area among group's top destinations. Retrieved from. http://www.washingtonpost.com/local/africanimmigrant-population-doubling-each-decade-washington-area-amonghighest/2014/10/01/efbada70-498f-11e4-891d-713f052086a0_story.html.

3. United States Census Bureau. African-Born Population in US Roughly Doubled Every Decade Since 1970. Retreived from http://www.census.gov/newsroom/press-releases/2014/cb14184.html.

4. Increasing the cultural competence of health care providers serving Minnesota's diverse populations. StratisHealth http://culturecareconnectionorg/matters/diversity/ethiopianhtml.

5. Carrie Lovgren McGuigan. Ethnomed. Diabetes in the Eritrean and Ethiopian Community: Cultural Information and Recommendations for Diabetes Educators (2010).Retrieved from https://ethnomed.org/clinical/diabetes/diabetes-in-the-eritrean-andethiopian-community-cultural-information-and-recommendations-for-diabetes-educators. .

6. Blanas DA, Nichols K, Bekele M, Lugg A, Kerani RP, Horowitz CR. HIV/AIDS among African-born residents in the United States. J Immigr Minor Health. 2013 Aug;15(4):718-24. PubMed PMID: 22821074. Pubmed Central PMCID: 3672242.

7. Beyene Y. Potential HIV risk behaviors among Ethiopians and Eritreans in the diaspora: A bird's-eye view. Northeast African Studies. 2000;7(2):119-42. 
8. Hyre AD, Krousel-Wood MA, Muntner P, Kawasaki L, DeSalvo KB. Prevalence and Predictors of Poor Antihypertensive Medication Adherence in an Urban Health Clinic Setting. The Journal of Clinical Hypertension. 2007;9(3):179-86.

9. Thames AD, Moizel J, Panos SE, Patel SM, Byrd DA, Myers HF, et al. Differential Predictors of Medication Adherence in HIV: Findings from a Sample of African American and Caucasian HIV-Positive Drug-Using Adults. AIDS Patient Care and STDs. 2012;26(10):621-30. PubMed PMID: PMC3462386.

10. Samet JH, Libman H, Steger KA, Dhawan RK, Chen J, Shevitz AH, et al. Compliance with zidovudine therapy in patients infected with human immunodeficiency virus, type 1: a cross-sectional study in a municipal hospital clinic. The American journal of medicine. 1992;92(5):495-502.

11. Oberguggenberger AS, Sztankay M, Beer B, Schubert B, Meraner V, Oberacher H, et al. Adherence evaluation of endocrine treatment in breast cancer: methodological aspects. BMC cancer. 2012 Oct 15;12:474. PubMed PMID: 23066928. Pubmed Central PMCID: PMC3519669. Epub 2012/10/17. eng.

12. Al-Qazaz HK, Hassali MA, Shafie AA, Sulaiman SA, Sundram S, Morisky DE. The eight-item Morisky Medication Adherence Scale MMAS: Translation and validation of the Malaysian version. Diabetes research and clinical practice. 2010 09/15;90(2):216-21. PubMed PMID: PMC3109726.

13. Ali-Al-Matari R MM, Daftary M, Wingate L, Ettienne E. (2018). Development and Validation of Amharic Version of the Simplified Medication Adherence Questionnaire among literate in Amharic speaking persons in an urban teaching hospital. International Journal of Case Reports \& Short Reviews. 
14. Wu JR, Moser DK, Chung ML, Lennie TA. Predictors of medication adherence using a multidimensional adherence model in patients with heart failure. J Card Fail. 2008 Sep;14(7):603-14. PubMed PMID: 18722327. Pubmed Central PMCID: PMC2603618. Epub 2008/08/30. eng.

15. Pluhar E, Yeager KA, Corkran C, McCarty F, Holstad MM, Denzmore-Nwagbara P, et al. Implementation of Audio Computer-Assisted Interviewing Software in HIV/AIDS Research. The Journal of the Association of Nurses in AIDS Care : JANAC. 2007;18(4):51-63. PubMed PMID: PMC2075082.

16. Waruru AK, Nduati R, Tylleskar T. Audio computer-assisted self-interviewing (ACASI) may avert socially desirable responses about infant feeding in the context of HIV. BMC Med Inform Decis Mak. 2005;5:24. PubMed PMID: 16076385. Pubmed Central PMCID: PMC1190182. Epub 2005/08/04. eng.

17. Minnis AM, Muchini A, Shiboski S, Mwale M, Morrison C, Chipato T, et al. Audio computer-assisted self-interviewing in reproductive health research: reliability assessment among women in Harare, Zimbabwe. Contraception. 2007 Jan;75(1):59-65. PubMed PMID: 17161126. Epub 2006/12/13. eng.

18. Lessler, J.T., Caspar, R.A., Penne, M.A., \& Barker, P.R. (2000). Developing computer assisted interviewing (CAI) for the National Household Survey on Drug Abuse. Journal of Drug Issues, 30 (1):9-33.

19. Aquilino WS. Interview mode effects in surveys of drug and alcohol use: A field experiment. Public Opinion Quarterly. 1994;58(2):210-40.

20. Hochstim JR. A critical comparison of three strategies of collecting data from households. Journal of the American statistical Association. 1967;62(319):976-89. 
21. Williams ML, Freeman RC, Bowen AM, et al. A comparison of the reliability of selfreported drug use and sexual behaviors using computer-assisted versus face-to-face interviewing. AIDS Education and Prevention. 2000;12(3):199-213.

22. van de Wijgert J, Padian N, Shiboski S, Turner C. Is audio computer-assisted selfinterviewing a feasible method of surveying in Zimbabwe? International journal of epidemiology. Oct 2000;29(5):885-890.

23. Osterberg L, Blaschke T. Adherence to medication. N Engl J Med. 2005 Aug 4;353(5):487-97. PubMed PMID: 16079372. Epub 2005/08/05. eng.

24. Brown MT, Bussell JK. Medication Adherence: WHO Cares? Mayo Clin Proc. 2011 Apr;86(4):304-14. PubMed PMID: 21389250. Pubmed Central PMCID: Pmc3068890. eng. 25. Eticha T, Teklu A, Ali D, Solomon G, Alemayehu A. Factors associated with medication adherence among patients with schizophrenia in Mekelle, Northern Ethiopia. PLoS One. 2015;10(3):e0120560. PubMed PMID: 25816353. Pubmed Central PMCID: PMC4376899. Epub 2015/03/31. eng.

26. Lifson AR, Demissie W, Tadesse A, Ketema K, May R, Yakob B, et al. Barriers to retention in care as perceived by persons living with HIV in rural Ethiopia: focus group results and recommended strategies. J Int Assoc Provid AIDS Care. 2013 Jan-Feb;12(1):32-8. PubMed PMID: 22993233. Epub 2012/09/21. eng.

27. Karliner LS, Auerbach A, Nápoles A, Schillinger D, Nickleach D, Pérez-Stable EJ. Language barriers and understanding of hospital discharge instructions. Medical care. 2012;50(4):283. 
28. Chaumba J. Health status, use of health care resources, and treatment strategies of Ethiopian and Nigerian immigrants in the United States. Soc Work Health Care. 2011;50(6):46681. PubMed PMID: 21774587. Epub 2011/07/22. eng.

29. Balfour L, Kowal J, Tasca GA, Cooper CL, Angel JB, Macpherson PA, et al. Development and psychometric validation of the HIV Treatment Knowledge Scale. AIDS Care. 2007 Oct;19(9):1141-8. PubMed PMID: 18058398. Epub 2007/12/07. eng.

30. Hareri HA, Gedefaw M, Simeng B. Assessment of prevalence and associated factors of adherence to anti-hypertensive agents among adults on follow up in Adama Referal hospital, East Shoa, Ethiopiacross sectional study. Int J Curr Microbiol App Sci. 2014;3(1):760-70.

31. Bezabhe WM, Peterson GM, Bereznicki L, Chalmers L, Gee P. Adherence to antiretroviral drug therapy in adult patients who are HIV-positive in Northwest Ethiopia: a study protocol. BMJ open. 2013;3(10):e003559.

32. Norman SA, Marconi KM, Schezel GW, Schechter CF, Stolley PD. Beliefs, social normative influences, and compliance with antihypertensive medication. Am J Prev Med. 1985 May-Jun;1(3):10-7. PubMed PMID: 3870899. Epub 1985/05/01. eng.

33. Lee JWR, Brancati FL, Yeh H-C. Trends in the Prevalence of Type 2 Diabetes in Asians Versus Whites: Results from the United States National Health Interview Survey, 1997-2008. Diabetes Care. 2011;34(2):353-7. PubMed PMID: PMC3024348.

34. Alene M, Wiese MD, Angamo MT, Bajorek BV, Yesuf EA, Wabe NT. Adherence to medication for the treatment of psychosis: rates and risk factors in an Ethiopian population. BMC Clin Pharmacol. 2012 Jun 18;12:10. PubMed PMID: 22709356. Pubmed Central PMCID: PMC3416691. Epub 2012/06/20. eng. 
35. Katz IT, Ryu AE, Onuegbu AG, Psaros C, Weiser SD, Bangsberg DR, et al. Impact of HIV-related stigma on treatment adherence: systematic review and meta-synthesis. Journal of the International AIDS Society. 2013;16(3Suppl 2):18640. PubMed PMID: PMC3833107.

36. Singh N, Squier C, Sivek C, Wagener M, Nguyen MH, Yu VL. Determinants of compliance with antiretroviral therapy in patients with human immunodeficiency virus: prospective assessment with implications for enhancing compliance. AIDS Care. 1996 Jun;8(3):261-9. PubMed PMID: 8827119. Epub 1996/06/01. eng.

37. Kulkarni SP, Alexander KP, Lytle B, Heiss G, Peterson ED. Long-term adherence with cardiovascular drug regimens. Am Heart J. 2006 Jan;151(1):185-91. PubMed PMID: 16368315. Epub 2005/12/22. eng. 